\title{
LA TRASCENDENCIA EN LA OBRA DE OROZCO
}

\author{
P O R
}

JUSTINO FER NÁ N DEZ

CuAndo la muerte nos conmueve, tal conmoción es reveladora en algún sos casos. Pero, reveladora ¿ de qué?; ciertamente no de misterio alguno del "más allá", sino de la persona amada que ha muerto. Asi, de golpe, se me ha presentado más de una vez su vida y el sentido que pudo haber tenido para el que ha terminado sus dias; pero, más seguramente, el sentido que aquella vida conocida tiene para mí.

Ante la mue de un artista de la categoría de José Clemente Orozco, cuyo trato casi cotidiano por muchos años supondría un conocimiento a fondo del hombre, * se ha renovado en mi una pregunta con la ctal me he debatido por largo tiempo frente a su obra: ¿qué sentido tiene, defini-

* Para quien se interese en mi interpretación general de la obra del artista, puede consultar mis trabajos siguientes: J.C. Orozco. Forma $e$ Idea. Edit. Lib. de Porrúa Hnos. y Cía México, 1942. Obras de J. C. Orozco en la Colección Carrillo Gil. México, 1949. Orozco, genio de América. Cuadernos Americanos. Atio vili. Nब 6. Novi: Dic., 1949. México' 
tivamente, en Orozco la trascendencia? Porque ante lo supremo del momento límite, no cabe sino preguntarse ¿cómo sintió, pensó e imaginó Orozco la trascendencia de esta vida?

En su obra hemos de encontrar suficientes elementos para dirimir la cuestión, que a menudo he columbrado, pero que ahora me resulta imperativo su esclarecimiento. La contestación de un tipo o de otro, negativa o afirmativa, clara o confusa, no está garantizada sino por la consideración e interpretación del desarrollo de su vida y de su obra, ésta bien elocuente y central expresión de su ser. Una primera exploración nos arrojará algún resultado, lancémonos a ella en la actitud de acercamiento amistoso con el artista, según lo que Sócrates, el maestro, preconizaba que habia de ser el diálogo; y que sea Orozco mismo quien me perdone si yerro.

Orozco nació a la conciencia en el ambiente tradicional religioso que nos es común a muchos mexicanos, tuvo, pues, una experiencia inicial en ese sentido, nada despreciable por cuanto a la forma en que su espíritu había de desarrollarse. Después no tenemos otros datos que sus caricaturas politicas y sus primeros dibujos (c. 1913), acuarelas y algún óleo, obras todas estas últimas que se ocupan en escenas de la vida, de "la vida galante" especialmente, en que la mujer es el tema principal y en que una cierta picardía subraya la intención realista. Ahora bien, las caricaturas como tales lo que acusan es la independencia de actitud y de carácter con que nació Orozco para la vida y para el arte; espíritu objetivante, realista y nada ilusorio, no participaba en la politica inmediata sino como testigo de situaciones, aunque en su expresión dejaba de ser eso para convertirse en un flagelador, en el sentido crítico que le dictaba su conciencia frente a la circunstancia.

Pues bien, lo anterior ya nos proporciona un primer perfil del hombre: realista, independiente y capaz de tomar decisiones personales en las circunstancias, decisiones de tipo crítico que he dan ya un matiz original a sus actitudes. Pero, ¿de qué realidad se habla?, pues, nada más ni rada menos que de la existencia humana en tal o cual circunstancia, de eso que con un término universal designamos como "la vida".

E1 arte de Orozco se alejó, desde su inicio, del naturalismo, esto es patente, pero no de aquella realidad, la existencia, es decir que expresaba una realidad más honda y auténticamente humana que la mera objetiva, una realidad moral, espiritual, que el rechazo de ins formas naturales $y$ 
al mismo tiempo la referencia a ellas hace resaltar. Asi, todas sus obras de "la vida galante", sus formidables imágenes de prostitutas y de sus ambientes, tienen la picardía, la sensualidad y la sexualidad suficientes para hacerlas bien reales, pero no "realistas" en el viejo sentido objetivista del concepto; tienen realidad humana, es decir, carácter moral y espiritual. Por eso, en última instancia, Orozco expresa "la vida galante" con la naturalidad de un hombre de mundo, como algo que se da así mas, por la libertad de sus formas expresivas subraya ante todo el carácter y el saldo es : vulgaridad, ridiculez, encanto sexual a veces, sólo a veces, distracción, aturdimiento y drama, poniendo en todo un grano de buen humor. Jamás estas imágenes son procaces, por el contrario revelan un espíritu humano, "demasiado humano", pero un espiritu.

Podemos decir, pues, que Orozco trasciende el mundo natural objetivo desde un principio y que revela, con sentido crítico, en la imagen del vicio mismo la trascendencia del carácter moral y del espíritu, más allá de la circunstancia inmediata. Comprendida así su expresión, su propio ser en movimiento continúa su vida libremente y registra escenas violentas de la Revolución Mexicana en una serie de dibujos espléndidos (1915-18), dramáticos o trágicos cuyo resultado, realista por demás, es ese: el drama y la tragedia humanos, el dolor, la injusticia, la brutalidad. Eso es lo que trasciende en sus dibujos, y no hay más, aunque supondriamos los sentidos contrarios: la alegría, la justicia y' la finura, como valores, pero si no queremos extralimitarnos, por ahora tenemos que conformarnos con lo que el artista expresa; sin embargo, con frecuencia se hace sentir en sus obras algo así como el destino, la incógnita del último sentido de toda circunstancia o actitud de la vida misma.

Cuando Orozco empezó su carrera de muralista (Preparatoria, 1922), aquel sentido trascendente que emanaban sus obras, todas expresiones de concretas situaciones históricas, se perfila y alcanza los más altos vuelos. Los nuevos ideale del tiempo van unidos al drama y la tragedia, y trascienden la necesidad de renovar la vida, renovación que como hermano siamés lleva pegado a su espalda al dolor. Pero no hay más, es la expresión dramática de unas circunstancias históricas, cuya realidad más profunda es revelada por el artista; tal realidad, a su vez, no tiene explicitamente en las obras sentido trascendente, en cuanto a que su existencia sea o no justificada por algo transhumano; todo trasciende humanidad, pero no transhumanidad. Otra vez el destino y la incógnita. Se trata totalmente de esta vida $\mathrm{y}$ este mundo. 
Orozco debe haberse preguntado, por entonces, si Cristo era todavía válido, y la contestación que se dió fué negativa; porque cuando Cristo destruye su crus, que es su obra y que es su sentido, queda descartado por el artista como posibilidad de salvación histórica. ¿ Se trata de la rebeldía contra la tradición? Es evidente que la posible trascendencia de arriba a abajo, digamos, no la encontró el artista en el mundo religioso tradicional. La pregunta era oportuna y tenía sentido cuando se trataba de construir una vida nueva.

La trascendencia de la Conquista está en el mundo humano creado por ésta en América; la de la evangelización está en el sentido caritativo de los hombres, todos como valores históricos, y como realidad vital; no va más allá.

Por primera vez surge claramente la trascendencia en la obra de Orozco cuando pintó un mural con el tema: Omnisciencia (Casa de los Azulejos, 1925), y en ese caso, lo que trasciende no es el hombre, sino 4.l "más allá", de donde nos son entregados graciosamente el cuerpo, el espíritu, la conciencia y otras potencias, el sentido de justicia, la sabiduría, la resignación. Es un momento en que Orozco considera aquella posibilidad y con ella se queda.

Con Prometeo (Pomona College, 1930), es la conciencia humana, simbolizada por el fuego entregado a los mortales, de la que trasciende toda actitud o actividad; ella nos hace pasivos o pasionales; es el pibote de la vida humana.

En la New School for Social Research (1931) hay una figura que simboliza la Ciencia, y que expresa la necesidad de las revelaciones trascendentes desde el "más allá", la divinidad quizá, para alcanzar algún conocimiento. Segundo caso de trascendencia de arriba a abajo, digamos.

América, antes y después de serlo, se presenta como una serie de tiempos históricos de sentido bárbaro y brutal (Dartmouth College, 1932), desde el remoto pasado indígena hasta el presente, salvo dos momentos: el de la aparición y fuga de Quetzalcoatì y el de la aparición de Cristo con la Conquista, ideal desdeñado por el mundo moderno, mecanicista y cientificista. Una vez más Cristo destruye su cruz. Es decir, que aquella primera decisión de Orozco en los muros de la Preparatoria conviene al tema del mundo americano y en él cobra nuevo sentido. $Y$, o el hombre es capaz de liquidar su presente, de trascender el mundo contemporáneo de mecanismos, de caos, de horror y de inconsciencia, renovándose ( $\mathrm{Pa}$ lacio de Bellas Artes, 1933), o no queda más que el imperio de eso. 
El hombre se trasciende en su obra y se quema en el fuego de su conciencia, justamente por necesidad de trascenderse en la vida, porque su vida es trascendente por constitución, y por ansia e impotencia de trascender el "más allá", de donde proviene la angustia. Por eso la cúpula del Hospicio Cabañas, en Guadalajara (1939), es sintesis magnifica de la idea de trascendencia en Orozco, en su sentido más central y general.

Historia y trascendencia, que es tanto como decir hombre, son indivisibles, junto con la conciencia y las posibilidades de los modos de ser. Así, Orozco, siempre metido en la historia, concibe a México como una conciencia trascendente a todas las virtudes e infortunios, a todas las maldades y las falacias, asi es en Jiquilpan (1940). La conciencia de México trasciende todo materialismo, riqueza o pobreza, en los muros de la Suprema Corte (1941) y alli el artista también expresa el ideal del movimiento del trabajo: trascenderse, esfuerzo inútil quizá, y allí, una vez más, desde lo alto trasciende la justicia, simbolizada por el fuego, mientras en lo bajo trasciende su contraria y la perversidad.

La última vez que aparece en los muros y bóvedas de Orozco un sentido trascendente de arriba a abajo, es en la ex-iglesia del Hospital de Jesús (1944). Trascendencia apocalíptica de castigo y dolor, en que el demonio reaparece como fuerza activa en este desventurado mundo contemporáneo. Ahora bien, la sexta y última exposición del artista en EL COLEGIO NACIONAL (1948), fué definitiva en el aspecto que venimos tratando. Con mayor vehemencia que nunca, si cabe, en una serie de dibujos y pinturas expresó su sentido anticlerical, y una imagen de Cristo más deshecha y torturada de cuantas conoce la historia parecia, en el conjunto, una recriminación; no era Cristo que destruía su Cruz ahora sino otros los que trascendiéndose destruian a Cristo. Con un solo cuadro, Orozco puso punto final al tema del "más allá"; una obra magistral, elocuente, stgnificativa, y de una sencillez pasmosa: un paisaje, un poco de tierla, una linea de horizonte, un amplio celaje, y en él un agujero negro, más o menos construído, que parecía una ventana abierta al infinito. Esta fué su última meditación y su conclusión final: la imposibilidad humana de trascender lo infinito, el "mas allá. El hombre construye ventanas, y se asoma y encuentra... la oscuridad, el misterio. No es obra de afirmación ni de negación, no se puede afirmar ni negar si hay algo o no hay nada "más allá", pero si se puede comprobar la impotencia humana para trascender lo transhumano. 
No es aventurado decir ahora: que por su sentido crítico y realista de la existencia humana, Orozco fué consciente de la trascendencia moral y espiritual del hombre hacia varias posibilidades -que posotros podemos o no calificarlas de buenas o malas-, todas pertenecientes a este mundo; que con sentido histórico desechó la posibilidad ofrecida por Cristo; que ante la brutalidad del mundo moderno insistió en el tema, como si fuese un mundo indigno del Crucificado, como si su obra y su sentido fuesen ya imposibles en él ; que no sólo se refirió así al mundo moderno, sino a la tradición medieval como actora también en la destrucción del Nazareno; que esa serie de meditaciones fué algo así como decir : entre todos hemos acabado con Cristo.

La visión ante Dios no le impidió, como gran artista que era, la ejecución de varias Crucifixiones (1942), de una escena del Via Crucis y de una Resurrección de Lázaro, perfectamente ortodoxas y de un gran valor como pinturas religiosas de nuestro tiempo.

Pensar groseramente que Orozco era un materialista o un atco sería craso error, porque toda su obra tiene sentido espiritual, y está transida del sentimiento de algo desconocido y sobrehumano que trasciende a este mundo del hombre.

En resumen tenemos, pues, que hay en Orozco: 1) una conciencia de la trascendencia del hombre sobre la naturaleza, realidad natural llamada "objetiva"; 2) una conciencia de la trascendencia del hombre en la historia, su propia vida y quehacer; 3) un sentimiento de la trascendencia de algo "más allá" en el mundo humano, creadora del hombre mismo; 4) una conciencia de la imposibilidad del hombre de trascender el "más allá".

En términos más llanos diriamos: que Orozco tuvo un sentimiento de Dios, dado dentro de la existencia humana, como no puede ser de otro modo, y una conciencia de ésta como un haz de posibilidades en actividad operando en la historia y sobre la naturaleza, y una conciencia de la limitación humana para conocer a Dios, mas no para sentirlo. En última instancia, el sentido crítico y realista de Orozco profundizó en la existencia humana, y fué consciente de las posibilidades y limitaciones del hombre; por eso su obra es humanista por los cuatro costados, y revela no 


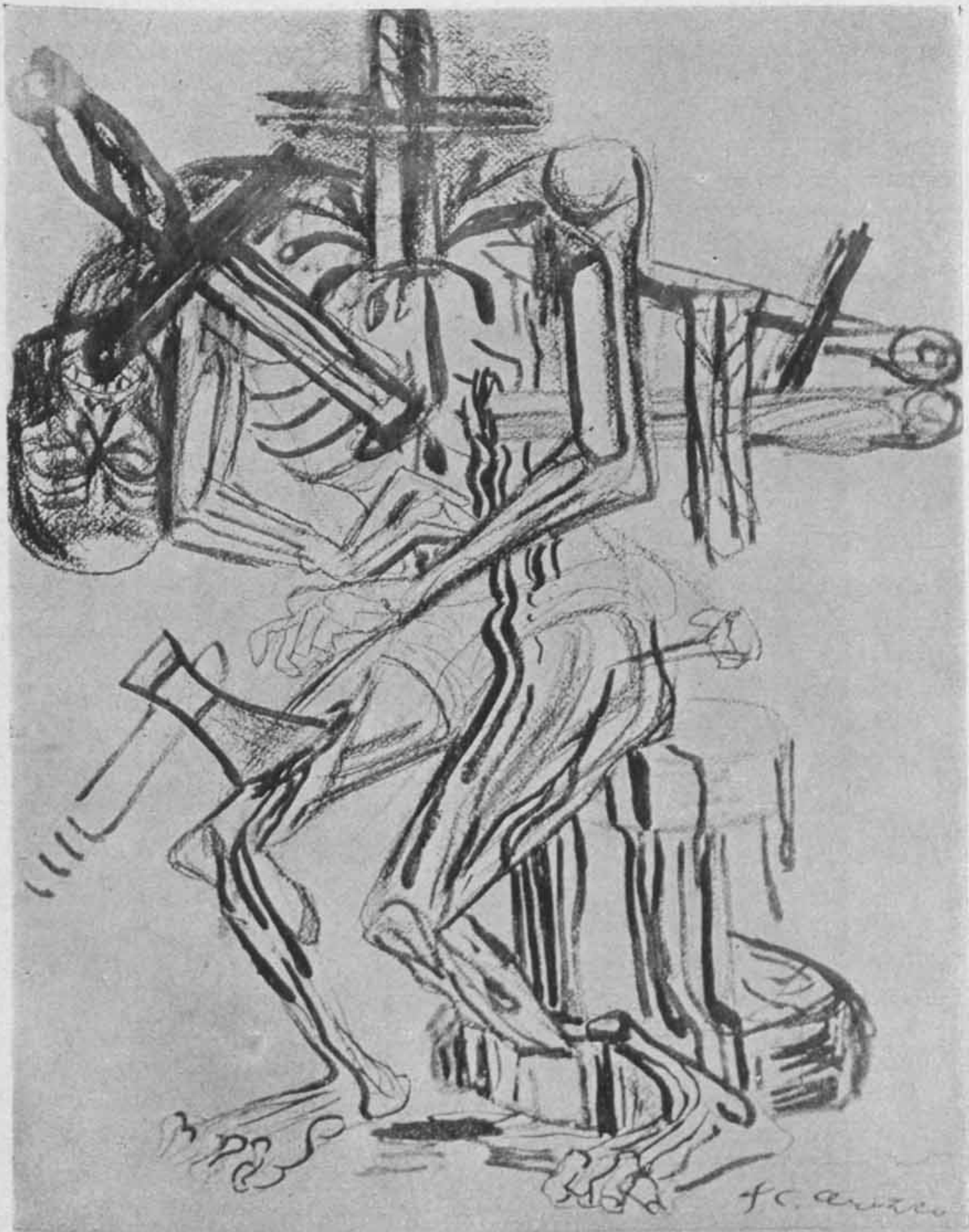

1. I. C. Orozco. Dibujo, 1948. (Fot. Luis Márquez) 


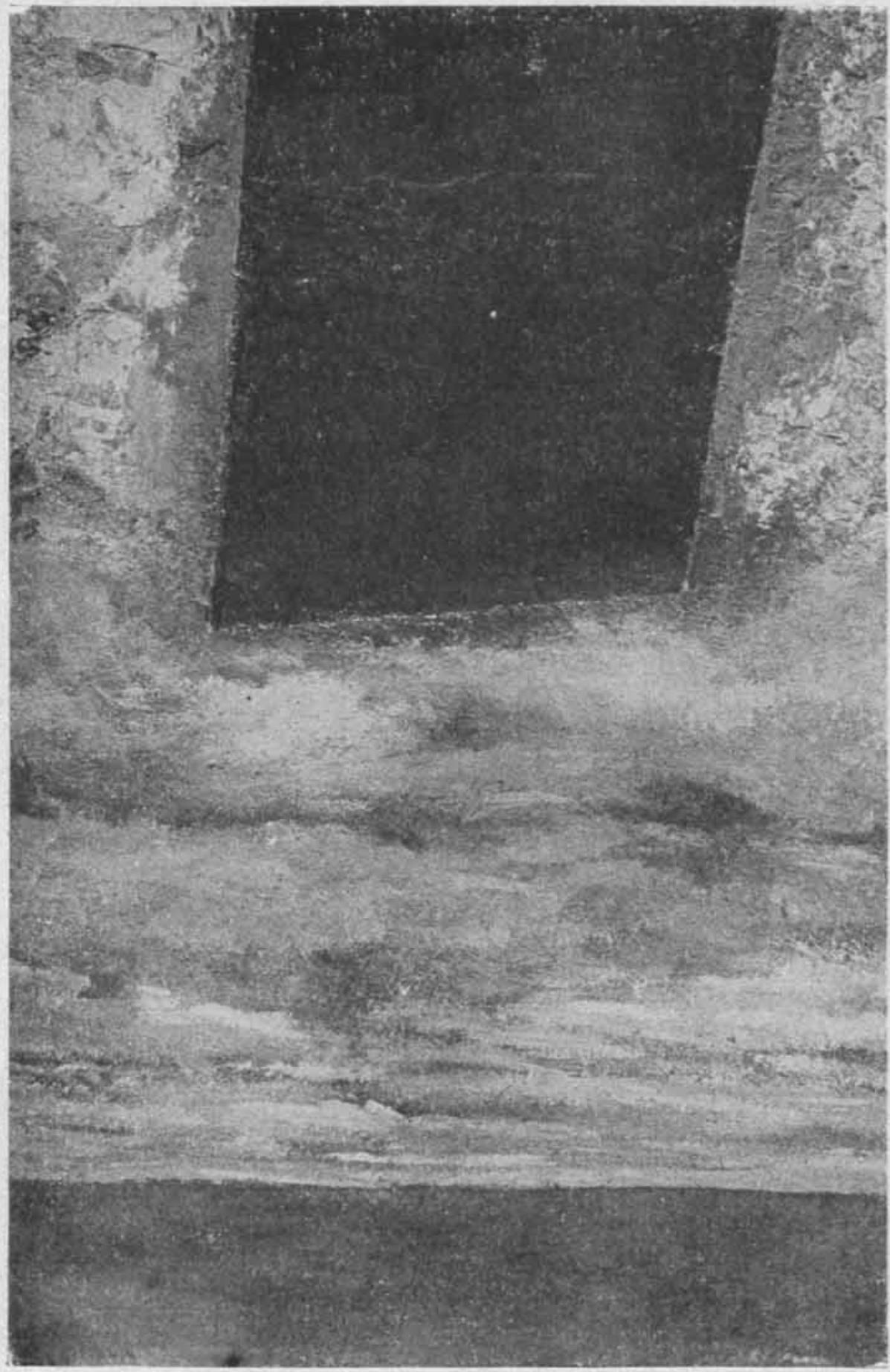

2. J. C. Orozco. Paisaje, 1948. (Fot. Luis Márquez) 
sólo la conciencia de Orozco, sino de de todo un sector coincidente de la conciencia contemporánea que vive ese drama, hecho que puede ser documentado.

El pensamiento de Orozco, en lo que se refiere al "más allá", coincide con las mejores corrientes contemporáneas; si se me permite ser irrespetuoso diré que es la filosofía de: "lo más seguro es ¿quién sabe?”, para decirlo en términos de una certera expresión popular mexicana que gustaría él oirla, sabedor como era de que la sabiduría popular no se engaña.

Por ser realista, y por no ser ilusorio, se la ha tachado de ser falto de ideales y de no ofrecer solución, consuelo o esperanza alguna al presente, porque el público siempre busca eso; pero su ideal fué penetrar en la realidad humana, histórica, $y$ atenerse a las verdades descubiertas $y$ expresarse así, con toda sinceridad y honradez, y su esperanza estaba radicada en la actualidad del movimiento, que todo lo cambia volviendo lo negro blanco y viceversa; algo así como el viejo adagio de que "no hay mal que dure cien años ni paciente que lo resista".

El movimiento en Orozco está en directa relación con la trascendencia, porque ya sea ésta del hombre en la historia y sobre la naturaleza, o el sentimicnto de algo que trasciende desde "el más allá" en el hombre y la naturaleza, se trata de la trascendencia en acto continuo, deste el desconocido principio hasta el desconocido fin,-como el artista dijera en alguna ocasión-, y por tanto en movimiento. No debe identificarsc el mero sentimiento de algo posible o no "más allá" con el Primer Motor aristotélico. En Orozco no queda substancialismo o esencialismo alguno, no queda sino el movimiento en la historia que es la única realidad de verdad, si alguna, que tenemos entre manos, por eso es Orozco un hombre de hoy $y$ en su arte lleva a un extremo el mindo moderno, y al coincidir con otros, con otras corrientes de nuestro tiempo, es uno de los principales actores y creadores de la época contemporánea, cuya prolongación es imprevisible, pero cuyo cambio, a la larga, es seguro.

Se podrá coincidir, o no, con el pensamiento y el sentimiento de Orozco; pero lo que no se podrá es negarle la sinceridad, la profundidad y la oportunidad que tienen sus meditaciones $y$, por otra parte, es inevitable que un pensamiento así aparezca en un tiempo de aguda crisis de conciencias como es el presente, por eso es certero.

Si no yerra el sentimiento de trascendencia de arriba a abajo, si el ser honrado y sincero y amar la verdad, de acuerdo con su conciencia, y 
ser gran artista, son valores que cuentan en "el más allá", Orozco ha de haber encontrado un lugar entre los buenos, que nunca son muchos y menos tan grandes como él. Que haya tenido el denuedo de hablarnos como nos habló y en formas tan originales y grandiosas, es la mejor prueba del temple de su espíritu y de su potencia creadora. 